Nikola Radivojević ${ }^{1}$

Nikola Ćurčić ${ }^{2}$

Marija Marčetić ${ }^{3}$
JEL: G24, C22, C52, C53

DOI: 10.5937/industrija46-16666

UDC: $339.13(497-15)$

005.334

Original Scientific Paper

\title{
Quantifying Extreme Market Risk in the selected Western Balkan Countries
}

\author{
Article history: \\ Received: 25 February 2018 \\ Sent for revision: 26 March 2018 \\ Received in revised form: 10 May2018 \\ Accepted: 10 May2018 \\ Available online: 29 June 2018
}

\begin{abstract}
The purpose of this paper is to investigate the performance of unconditional and conditional Value at Risk (VaR) and Expected Shortfall (ES) models based on EVT. The application of one unconditional VaR and ES model based on EVT and three variants of conditional models of VaR and ES based on EVT in the capital markets of the selected WBC was tested in the paper. To test the VaR model, a conditional and unconditional cover test was used, with the note that their results were subject to verification using the Monte Carlo test procedure. The obtained results suggests that these models can be successfully used to quantify extreme market risk in selected markets, in the context of Basel standards. ES models have been tested and ranked using loss function. By using the Bootstrap simulation, these results are subject to verification. The obtained results does not reveal which model is most suitable for the selected markets, since they are differently ranked in different markets.
\end{abstract}

Key words: Value at risk, Expected Shortfall, Extreme Value Theory, market risk

\section{Kvantifikovanje ekstremnov tržišnog rizika na izabranim zemljama Zapadnog Balkana}

Apstrakt: Cilj rada je da se ispita uspšnost bezuslovnog i uslovnih VaR i ES modela zasnovanih na EVT. $U$ radu je testirana aplikativnost jednog bezuslovnog VaR i ES modela zasnvana na EVT i tri varijante uslovnih

\footnotetext{
${ }^{1}$ Technical college at applied studies, Kragujevac, radivojevic034@gmail.com

${ }^{2}$ Faculty of Management, Sremski Karlovci

${ }^{3}$ High School of Business Studies, Blace 
modela VaR i ES zasnovanih na EVT na tržištima kapitala izabranih zemalja Zapadnog Balkana. Za testiranje VaR modela korišćen je test uslovnog $i$ bezuslonog pokrića, uz napomenu da su njihovi rezultati podvrgnuti verifikaciji primenom Monte Carlo test procedure. Dobijeni podaci sugerišu da se ovi modeli mogu uspešno koristiti za kvantifikovanje ekstemnog trežšinog rizika na izabranim tržišitma, u kontekstu Bazelskih standarda. ES modeli su testirani i rangirani primenom fukcije gubitka. Primenom bootstrap simulacije ovi rezultati su podvrgnuti verifikacji. Dobijeni podaci ne otkrivaju koji je model najadekvatniji za izbrana tržišta, budući da su na različitim tržištima različito rangirani.

Ključne reči: Vrednost pri riziku, očekivani gubitak, teorija ekstremne vrednosti, tržištni rizik

\section{Introduction}

Basel Committee on Banking Supervision, since 1988, has brought a series of instructions and amendments, known as Basel Standards, with the aim of developing a system of rules and standards that will be a mechanism for improving the stability of the financial system, establishing equitable market conditions for the operation of international banks by defining uniform solvency coefficients and defining the role of regulators in situations with unclear jurisdictions, as no bank with subsidiaries in different jurisdictions could escape control and audit. By these standards, banks are allowed to determine capital adequacy to cover market risks by applying $\mathrm{VaR}$ and Expected Shortfall (ES) models. These standards do not prescribe the type of risk models, but only the rule that relates to testing their validity. Owning the appropriate risk models does not matter only with the bank, but also for the whole economic system, especially when one takes into account the consequences of collapse of large banks on the stability of the financial system. However, the application of some, above all non-parametric VaR models, in emerging markets such as the financial markets of the WBC, is significantly limited. At best, such models can only produce unconditional coverage of market risk. The limitations are the consequence of, on the one hand, the characteristics of these markets (presence autoregressive conditional heteroscedastic (ARCH) effect, etc) and that is, the procedure on which these models are based, as regulatory requirements for market risk assessment, on the other hand (see more about this in Radivojevic). Numerous empirical research, such as were conducted by Radivojevic et al., 2016, 2017 and Rosiggnoli et al. $(2012,2013)$ show that extreme losses, in these markets, are happening more than predicted by theoretical distributions, which is a limiting fact for the use of numerous parametric models. 
In response to the fact that extreme losses occur more often than predicted by the assumption of normality, and that in this case VaR estimates are rather imprecise for extreme conditional levels, the group of authors, led by McNeil and Fray, advocates the use the VaR based on the theory of extreme value (EVT). The EVT studies extreme changes in the random variable. As such, it relates only to the distribution of the tail, not to the whole distribution. It represents an extension of the central limit theorem. The conventional and rough division of these models is on conditional and unconditional VaR and ES models based on EVT. However, these models have their own shortcomings and limitations. Hence, the aim of this paper is to examine the applicability of these two groups VaR and ES models. In the paper is tested applicability unconditional VaR and ES models based on EVT and three variants of conditional $\mathrm{VaR}$ and ES models based on EVT, on the capital markets of selected West Balkan countries (WBC).

\section{Literature review}

According to the advantages and disadvantages of the VaR and ES models based on EVT, the results of empirical research speaks, both in favor and against these models. The researches were conduted by Danielsson and de Vries (1997), Neftci (2000), Gencay et al. (2003, 2004) and Zikovic (2010) are in favor these models. Danielsson and de Vries (1997) compared the performance of the RiskMetrics model, the HS model and the EVT model. The results of their research reveal that RiskMetrics models are good when the $\mathrm{VaR}$ assessment is conducted for lower confidence levels. However, as the confidence level increases, their performance is weak in the sense that extreme losses are underestimated, while the HS models overestimate them. In the contrary to these models, as the confidence level increases, the VaR estimates obtained by EVT models are getting better and better. Similar results were presented by Neftci (2000), Harmantzis et al. (2006), as well as Marinelli (2007). They have shown that VaR EVT models provide better performance compared to parametric models and HS models. Gencay and Selcuk (2004) tested the performance of the unconditional EVT models on emerging markets. They found that EVR models provide better risk assessments than HS and parametric models based on variance-covariance matrices. Zikovic (2010) came to the same conclusions by studying the performance of the EVT model on the capital market of Croatia as well as in the crude oil market. Radivojević et al (2016) introduced the new EVT-based VaR model. The model was tested on the market capital of candidates and potential candidates for EU membership and showed that the model works pretty well. Şener et al. (2012) tested and ranked twelve different popular VaR models on the equity indexes of four European emerging markets, and found that asymmetric methods, such as CAViaR Asymmetric, generate the best 
performing VaR estimates. Similar findings were presented by Louzis et al. (2014). Their results provide evidence in favor of the Asymmetric HAR (Heterogeneous Autoregressive) realized volatility model combined with the EVT. Rossignolo et al. (2013) studied performances of the popular VaR models and EVT approach at PIGS countries, in terms of meeting the backtesting rules of Basel Committee. The results of their study suggest that regulatory authorities should determine the use of models which can capture the heavy tails (particularly EVT approach) and discourage or prohibit the use of the most popular VaR models, especially the VCV, the HS and the FHS models. Del Brio et al. (2014) studied the performances of the parametric and semi-parametric VaR models based on an ARMA-GARCH models and the Gram-Charlier expansion (GC), during the subprime and sovereign debt crises. Their findings support EVT approach and GC expansion. What both of these studies have in common is that the backtesting results were not subject to verification. Hence, this paper is the first paper of this kind in which this was done.

Interesting results were reported by Dimitrakopoulos et al (2010). They investigated the issue of market risk quantification for emerging and developed market equity portfolios and found that despite the documented differences between emerging and developed markets, the most successful VaR models are common for both asset classes. In the case of the emerging market, most VaR models turn out to yield conservative risk forecasts, in contrast to developed market equity portfolios, where most models underestimate the realized $\mathrm{VaR}$. VaR estimation during periods of financial turmoil seems to be a difficult task, particularly in the case of emerging markets and especially for the higher loss quartiles. VaR models seem to be affected less by crises periods in the case of developed markets. The performance of the parametric (non-parametric) VaR models improves (deteriorates) during post-crises periods due to the inclusion of extreme events in the estimation sample. They used a very wide spectrum of popular and widely used VaR models and compared them with EVT and adaptive filtered models.

The contrary to these results, are survey results by Lee and Saltoglu (2001). Testing the performance of standard VaR models and EVT models on the emerging markets (Indonesia, Korea, Malaysia, Taiwan, and Thailand), they have shown that HS produces better estimates than EVT models. To examine the validity of the models, they were used Christoffersen's conditional coverage model. 


\section{Extreme value theory}

From the point of view of risk management, focusing on extreme losses instead of the entire distribution is logical, as risk management involves measuring the economic impact of extreme events on the value of the portfolio. In this context, EVT indicates that the distribution of the random variable $(\mathrm{x})$ above a certain threshold exceeds $(\mathrm{u})$, provided that the threshold is sufficiently high and at the same time provides sufficient number of extreme yields $(\mathrm{y}=\mathrm{x}-\mathrm{u})$ can be approximated using asymptotic distribution of extreme values (see Balkema and de Haan , 1974). In the literature, this distribution is known as the general Pareto distribution (GPD):

$$
G_{\xi, \sigma, \mu}(x)= \begin{cases}1-\left(1+\xi \frac{x-\mu}{\sigma}\right)^{-\frac{1}{\xi}} & \text { за } \xi \neq 0 \\ 1-e^{-(x-\mu) / \sigma} & \text { за } \xi=0\end{cases}
$$

where are:

$x \quad$ - random variable for which the condition applies $x \geq 0$ for $\xi \geq 0$

$\mu \quad$ - location parameter;

$\sigma \quad$ - scale parameter;

$\xi \quad$ - tail index

Depending on the tail of distribution $(\xi)$, three special cases are distinguished:

1) when is $\xi>0$,

2) when is $\xi=0$ and

3) when is $\xi<0$.

For financial data, the most relevant Pareto distribution is with $\xi>0$, since it corresponds to fat tails. This type of distribution is known in the literature as an Fréchet distribution.

In the context of market risk management, previously it means that it is possible to estimate the distribution of extreme portfolios returns, without the need to make assumptions about the entire distribution of portfolio returns. In other words, EVT allows to assess the market risk associated with extreme events, or to determine the likelihood of extreme losses exceeding the defined threshold, using the following function:

$$
F_{u}(y)=\operatorname{Pr}(x-u \leq y \mid X>u)
$$


The estimation of market risk, which is associated with extreme losses with limited market data, is extremely difficult. It is becoming more and more difficult as extreme events are becoming increasingly rare. So one solution for risk estimation under these conditions is the use of an VaR models based on EVT. The advantage of these models in comparison with standard VaR models is precisely that they work directly with extreme losses and do not require assumptions about the entire distribution of portfolio returns. However, when using these models, one should bear in mind the constraints that the EVT paradigm imply. The EVT models are built on asymptotic arguments, so their application is limited when applied to a finite sample. In order to estimate the extreme risk, it use the result from asymptotic theory that for a sufficiently high threshold $(\mathrm{u}), \quad F_{u}(y) \approx G_{\xi, \sigma(u)}(y)$, where is $y=(x-u)$. An approximation of $\mathrm{F}(\mathrm{x})$, for $\mathrm{x}>\mathrm{u}$ can be obtained as:

$$
F(x)=[1-F(u)] G_{\xi, \sigma(u)}(y)+F(u)
$$

An estimate of $F(u)$ can be obtained non-parametrically by means of the empirical cumulative distribution function:

$$
\hat{F}(u)=(N-k) / N
$$

where are: $\mathrm{k}$ is the number of exceedances over the threshold $(U)$ and $(N)$ the number of observations.

By substituting equation (2) ) into equation (3) the following estimate for $F(x)$ is obtained:

$$
\hat{F}(u)=1 / \frac{k}{N}\left(1+\hat{\xi} \frac{x-\mu}{\hat{\sigma}}\right)^{-\frac{1}{\xi}}
$$

where $(\xi)$ and $(\xi)$ are the maximum likelihood estimators of $(\xi)$ and $(\sigma)$. This equation can be inverted to obtain a quantile of the underlying distribution, which is actually VaR. So, for $c l \geq F(u)$ the VaR is calculated using the following expression:

$$
V a R_{c l}=u+\frac{\sigma}{\xi}\left[\left(\frac{1-c l}{k / n}\right)^{-\xi}-1\right]
$$

where $(k)$ represents the number of exceeding over the defined threshold $(u)$, $(\sigma)$ is the scale parameter and $(n)$ the number of observations, or 
Radivojević N., et al.: Quantifying Extreme Market Risk in the selected Western Balkan

$$
V a R_{c l}=x_{(n-k)}\left(\frac{n}{k}(1-c l)\right)^{-1 / \hat{\alpha}^{H}}
$$

when the tail index $(\zeta)$ is estimated by the Hill estimator.

Assuming that tail index $(\zeta)$ is less than 1, an ES-EVT estimate is obtained by using the following equation:

$$
E S-E V T=\frac{V a R_{c l}}{1-\xi}+\frac{\sigma-\xi u}{1-\xi}
$$

To solve the problems of unconditional estimation VaR estimation based on the EVT, McNeil and Frey (2000) were suggested a conditional quantile EVT model, which based on the assumption that the tail of the conditional distribution of the underlying GARCH process is approximated by a heavytailed distribution. The model can be written as follows way:

$$
\begin{aligned}
& \operatorname{VaR}_{c l, t}=\mu_{t}+\sigma_{t} \operatorname{VaR}(Z)_{c l} \\
& \sigma_{t}^{2}=\alpha_{0}+\sum_{i=1}^{q} \alpha_{1} \varepsilon_{t-i}^{2}+\sum_{i=1}^{p} \beta_{i} \sigma_{t-i}^{2} \quad r_{t}=\mu_{t}+\sigma_{t} Z_{t} \\
& Z=\left(\frac{x_{t-n+1}-\mu_{t-n+1}}{\sigma_{t-n+1}}, \ldots, \frac{x_{t}-\mu_{t}}{\sigma_{t}}\right) \\
& \operatorname{VaR}(Z)_{c l}=u_{Z}+\frac{\sigma_{Z}}{\xi_{Z}}\left[\left(\frac{1-c l}{\bar{F}\left(u_{Z}\right)}\right)^{-\xi_{Z}}-1\right]
\end{aligned}
$$

Another limitation, which should be taken into account when using these models, is that the tail size, through the assessment of the tail index, affects the validity of the risk assessment. Sukcharoensin (2010) present this problem as a balance between the accuracy of the variance and the bias of the tail estimation. When the tail is increased, the threshold is moved to the middle of the distribution and a larger number of data is obtained. This increases the accuracy and reduces the variation in tail estimation, but at the same time increases its bias because greater importance is attributed to the central observations in relation to the tail events. Conversely, when the tail size decreases. When the size of the tail decreases, the bias decreases, but the variance increases as the number of observations decreases. In order to 
determine the optimal tail size, the solutions were proposed in their papers Embrechts et al. (2005) and Danielsson and de Vries (1997).

\section{Data, methodology and backtesting results}

Data used for testing applicability of unconditional and conditional VaR and ES models based on EVT are the daily logarithmic returns of stock indexes of selected the WBC such as Serbia, Montenegro and Croatia. The tested stock indexes are the BELEXline (Serbia), the MONEX20 (Montenegro) and the CROBEX (Croatia). The returns are collected from the official stock exchange web sites of these countries for the period between February, $1^{\text {st }} 2014$ to February, $1^{\text {st }}$ 2017. The calculated VaR and ES figures are for one-day ahead horizon for the period between February, $1^{\text {st }} 2015$ and February, $1^{\text {st }}$ 2016, according to the Basel III standard. The VaR and ES estimates made for the confidence levels of 99 and $97,5 \%$, retrospectively. The rest observations were used as resample observations needed for the $\mathrm{VaR}$ and ES starting values.

The unconditional VaR and ES estimations based on EVT, were obtained using the equation expression (6) and (7), until the conditional VaR and ES estimations based on EVT were obtained using the (8) and (7), with note that we employ three different $\mathrm{GARCH}$ processes. The first one, proposed by McNeil and Frey (2000), is defined without assuming any specific distribution for the innovations z (QMLE procedure); the second one assumes GED innovations and thrd, skewed $t$ innovations. The latter assumptions are justified because if we constrain the GDP shape parameter to be positive.

At the beginning of the analysis, the characteristics of selected markets for the entire observation period were analyzed. Table 1 gives a summary of the descriptive statistics and normality tests for each stock indexes. The descriptive statistics of the selected stock indexes confirm the results of the recent studies. The standard deviations, for two markets, are high, which is confirmed by the difference between minimum and maximum values The analysis of the shows that stock indexes have a significantly fatter distribution tails than assumed under normality. The values of excess kurtosis, ranging from 2,153, in the case of the BELEXline to 11,433 in the case of the BIRS index. In other words, all the analyzed stock indexes show a significant leptokurtosis. The skewness of all stock indexes is significantly different from zero, which indicates that the stock indexes have asymmetric returns. There is also evidence of negative skewness in the cases of Monex and Crobex index. It means that the left tails are particularly extreme. In order to examine formally whether returns follow the normal distribution, we employed the Jarque-Bera test. The value of the Jarque-Bera test indicates that we should reject the null hypothesis of normality providing the evidence that the return 
Radivojević N., et al.: Quantifying Extreme Market Risk in the selected Western Balkan

series are not normally distributed. In order to examine the presence of $\mathrm{ARCH}$ effect we used the Lagrange Multiplier for $\mathrm{ARCH}(1)$ model. The presence of $\mathrm{ARCH}$ effect first order was recorded only on the Montenegro market.

Table 1. Descriptive statistics of selected the WBC

\begin{tabular}{|l|c|c|c|}
\hline & BELEXline & MONEX & CROBEX \\
\hline Mean & 0,000 & 0,000 & 0,012 \\
\hline Standard Dev. & 0,006 & 0,008 & 0,491 \\
\hline Min & $-0,032$ & $-0,065$ & $-2,920$ \\
\hline Max & 0,025 & 0,033 & 1,850 \\
\hline Ex.kurtosis & 2,153 & 8,259 & 2,548 \\
\hline Skewness & 0,013 & $-1,044$ & $-0,274$ \\
\hline Jarque-Bera test & 145,65 & 2283,1 & 212,024 \\
\hline p-value & 0,000 & 0,000 & 0,000 \\
\hline ARCH effect (LM) & 0,506 & 29,532 & 0,489 \\
\hline p-value & 0,476 & 0,000 & 0,485 \\
\hline
\end{tabular}

Source: Authors' calculations

The estimated parameters of the volatility modes are shown in Table 2.

Table 2. The estimates of the parameters of $\operatorname{GARCH}(1,1)$ models

\begin{tabular}{|c|c|c|c|}
\hline & BELEXline & MONEX & CROBEX \\
\hline \multicolumn{4}{|c|}{ Parameters of $\operatorname{GARCH}(1,1)$} \\
\hline & $\begin{array}{l}0,083^{\star \star \star} \\
(0,026)\end{array}$ & $0,192^{* *}(0,078)$ & $0,076^{*}(0,056)$ \\
\hline & $\begin{array}{c}0,867^{* \star *} \\
(0,042)\end{array}$ & $0,723^{* * *}(0,083)$ & $0,539^{* *}(0,216)$ \\
\hline & $\begin{array}{c}1,7 e-06^{*} \\
(9,6 e-07)\end{array}$ & $\begin{array}{l}7,0 e-06^{\star *} \\
(3,0 e-06)\end{array}$ & $\begin{array}{c}0,093^{*} \\
(0,048)\end{array}$ \\
\hline \multicolumn{4}{|c|}{ Parameters of $\operatorname{GARCH}(1,1)-G E D$} \\
\hline & $0,091^{\star * *} \quad(0,029)$ & $0,161^{\star \star \star}$ & $0,063 \quad(0,058)$ \\
\hline & $0,846^{\star \star \star}$ & $0,730^{\star * *}$ & $(0,346)$ \\
\hline & $2,2 \mathrm{e}-06^{* * *}(1,1 \mathrm{e}-06)$ & $7,4 \mathrm{e}-06^{* *} \quad(2,9 \mathrm{e}-06)$ & $0,083 \quad(0,073)$ \\
\hline & $1,325^{\star \star *}(0,131)$ & $1,181^{* *}$ & $1,322^{* * *} \quad(0,106)$ \\
\hline \multicolumn{4}{|c|}{ Parameters of $\operatorname{GARCH}(1,1)-$ skew.t(d) } \\
\hline & $0,101^{* * *}$ & $0,153^{* * *}$ & $0,065 \quad(0,086)$ \\
\hline & $0,831^{\star \star *}$ & $0,735^{\star * \star}$ & $(0,652)$ \\
\hline & $2,4 \mathrm{e}-06^{* *} \quad 1,4 \mathrm{e}-06$ & $7,6 e-06^{\star *}(3,03 e-06)$ & $(0,142)$ \\
\hline & $6,428^{\star * *}$ & $4,899^{\star \star \star}$ & $5,830^{\star * *}$ \\
\hline & $0,108^{\star \star *}$ & $-0,088^{* * *} \quad(0,050)$ & $\begin{array}{ll}-0,041 \quad(0,051) \\
\end{array}$ \\
\hline
\end{tabular}

Note: In parentheses are shown standard errors. ${ }^{* * *},{ }^{* *},{ }^{*}$ denote significance at the $1 \%, 5 \%$ and $10 \%$ level, retrospectively. The parameters of the volatility models were rated by Quasi-maximum likelihood estimation

Source: Authors' calculations 
Radivojević N., et al.: Quantifying Extreme Market Risk in the selected Western Balkan

For estimating the tail index, we used the Hill estimator:

$$
\hat{\alpha}^{H}=\frac{1}{k} \sum_{i=1}^{k} \ln \left(x_{n-k+1}\right)-\ln \left(x_{n-k}\right)
$$

The threshold value for each index is determined by applying the rule of thumb for determining the threshold which was proposed by Christoffersen (2011). The threshold $(u)$ will then simply be the 95th percentile of the data set. This instruction is applied in the paper. The value of thresholds and the maximum likelihood estimates of the tail index and maximum likelihood estimates of the sigma, for each index and model, are presented in Table 3.

Table 3. The maximum likelihood estimates of the tail index and sigma, threshold value

\begin{tabular}{|c|c|c|c|}
\hline \multicolumn{4}{|c|}{ Unconditional EVT } \\
\hline & BELEXline & MONEX20 & CROBEX \\
\hline \multicolumn{4}{|l|}{ Parameters } \\
\hline Threshold value & $-1,463$ & $-1,468$ & $-1,636$ \\
\hline The tail index $(\xi)$ & 0,323 & 0,440 & 0,268 \\
\hline Sigma & 0,699 & 1,273 & 0,812 \\
\hline \multicolumn{4}{|c|}{ Condtional EVT/GARCH } \\
\hline Threshold value & $-2,2036$ & $-2,064$ & $-1,676$ \\
\hline The tail index $(\xi)$ & 0,4504 & 0,323 & 0,236 \\
\hline Sigma & 1,663 & 1,379 & 0,777 \\
\hline \multicolumn{4}{|c|}{ Condtional EVT/GARCH GED } \\
\hline Threshold value & $-2,3153$ & $-2,219$ & $\mathrm{~N} / \mathrm{A}$ \\
\hline The tail index $(\xi)$ & 0,4429 & 0,318 & $\mathrm{~N} / \mathrm{A}$ \\
\hline Sigma & 1,678 & 1,455 & $\mathrm{~N} / \mathrm{A}$ \\
\hline \multicolumn{4}{|c|}{ Condtional EVT/ GARCH(1,1)- skew.t(d) } \\
\hline Threshold value & $-2,367$ & $-2,255$ & $\mathrm{~N} / \mathrm{A}$ \\
\hline The tail index $(\xi)$ & 0,425 & 0,314 & N/A \\
\hline Sigma & 1,650 & 1,456 & $\mathrm{~N} / \mathrm{A}$ \\
\hline
\end{tabular}

Source: Authors 'calculations

For backtesting VaR we were used unconditional coverage test $\left(\mathrm{LR}_{\mathrm{uc}}\right)$ :

$$
L R_{u c}=2 \ln \left[(1-p)^{T-T_{1}} p^{T_{1}}\right]+2 \ln \left[\left(1-T_{1} / T\right)^{T-T_{1}}\left(T_{1} / T\right)^{T_{l}}\right]
$$

where $(p)$ is the tail probability; $T$ is total number estimation; $T_{1}$ is number of breaks, and conditional coverage test $\left(\mathrm{LR}_{\mathrm{uc}}\right)$ :

$$
L R_{c c}=L R_{u c}+L R_{\text {ind }}
$$


Radivojević N., et al.: Quantifying Extreme Market Risk in the selected Western Balkan

where $L R_{\text {ind }}=-2 \ln \left[(1-\pi)^{T_{00}+T_{11}} \pi^{T_{01}+T_{11}}\right]+2 \ln \left[\left(1-\pi_{01}\right)^{T_{00}} \pi_{01}^{T_{01}}\left(1-\pi_{11}\right)^{T_{01}} \pi_{11}^{T_{11}}\right]$

The backtesting results are presented in Table 4.

Table 4. The backtesting results for the $L R_{u c}$ test and the $L R_{c c}$ test

\begin{tabular}{|c|c|c|c|c|c|c|}
\hline & \multicolumn{6}{|c|}{ The $\mathrm{LR}_{\mathrm{uc}}$ test for $99 \% \mathrm{VaR}$} \\
\hline & \multicolumn{3}{|c|}{ Unc.EVT } & \multicolumn{3}{|c|}{ EVT- GARCH } \\
\hline Stock index & $\begin{array}{l}\text { No. of } \\
\text { breaks }\end{array}$ & $\begin{array}{c}\text { Critical value } \\
\text { of } L R_{u c}\end{array}$ & $\begin{array}{c}p- \\
\text { value }\end{array}$ & $\begin{array}{l}\text { No. of } \\
\text { breaks }\end{array}$ & $\begin{array}{c}\text { Critical value of } \\
\text { LR }_{u c}\end{array}$ & $p$-value \\
\hline BELEXline & 1 & 1,237 & 0,266 & 3 & 0,076 & 0,783 \\
\hline MONEX & 2 & 0,129 & 0,719 & 3 & 0,0756 & 0,783 \\
\hline \multirow[t]{2}{*}{ CROBEX } & 3 & 0,076 & 0,783 & $\mathrm{~N} / \mathrm{A}$ & $\mathrm{N} / \mathrm{A}$ & $\mathrm{N} / \mathrm{A}$ \\
\hline & \multicolumn{3}{|c|}{ EVT-GED } & \multicolumn{3}{|c|}{ EVT-GARCH-skew.t(d) } \\
\hline Stock index & $\begin{array}{l}\text { No. of } \\
\text { breaks }\end{array}$ & $\begin{array}{c}\text { Critical value } \\
\text { of } \mathrm{LR}_{\mathrm{uc}}\end{array}$ & $\begin{array}{c}\mathrm{p}- \\
\text { value }\end{array}$ & $\begin{array}{l}\text { No. of } \\
\text { breaks }\end{array}$ & $\begin{array}{c}\text { Critical value of } \\
L_{\mathrm{uc}}\end{array}$ & $p$-value \\
\hline BELEXline & 0 & $\mathrm{~N} / \mathrm{A}$ & $\mathrm{N} / \mathrm{A}$ & 0 & $\mathrm{~N} / \mathrm{A}$ & $\mathrm{N} / \mathrm{A}$ \\
\hline MONEX & 3 & 0,075 & 0,783 & 3 & 0,076 & 0,783 \\
\hline CROBEX & 2 & 0,129 & 0,719 & $\mathrm{~N} / \mathrm{A}$ & $\mathrm{N} / \mathrm{A}$ & $\mathrm{N} / \mathrm{A}$ \\
\hline \multicolumn{7}{|c|}{ The $\mathrm{LR}_{\mathrm{cc}}$ test for $99 \% \mathrm{VaR}$} \\
\hline & \multicolumn{3}{|c|}{ Unc.EVT } & \multicolumn{3}{|c|}{ EVT- GARCH } \\
\hline Stock index & $\begin{array}{l}\text { No. of } \\
\text { breaks }\end{array}$ & $\begin{array}{c}\text { Critical value } \\
\text { of } L R_{c c}\end{array}$ & $\begin{array}{c}p- \\
\text { value }\end{array}$ & $\begin{array}{l}\text { No. of } \\
\text { breaks }\end{array}$ & $\begin{array}{c}\text { Critical value of } \\
\qquad R_{\mathrm{CC}}\end{array}$ & $p$-value \\
\hline BELEXline & 1 & 1,239 & 0,538 & 3 & 0,076 & 0,963 \\
\hline MONEX & 2 & 0,129 & 0,937 & 3 & 0,076 & 0,963 \\
\hline \multirow[t]{2}{*}{ CROBEX } & 3 & 5,548 & 0,062 & $\mathrm{~N} / \mathrm{A}$ & $\mathrm{N} / \mathrm{A}$ & $\mathrm{N} / \mathrm{A}$ \\
\hline & \multicolumn{3}{|c|}{ EVT-GED } & \multicolumn{3}{|c|}{ EVT-GARCH-skew.t(d) } \\
\hline Stock index & $\begin{array}{l}\text { No. of } \\
\text { breaks }\end{array}$ & $\begin{array}{c}\text { Critical value } \\
\text { of } L R_{c c}\end{array}$ & $\begin{array}{c}\mathrm{p}- \\
\text { value }\end{array}$ & $\begin{array}{l}\text { No. of } \\
\text { breaks }\end{array}$ & $\begin{array}{c}\text { Critical value of } \\
\qquad R_{c c}\end{array}$ & p-value \\
\hline BELEXline & 0 & $\mathrm{~N} / \mathrm{A}$ & $\mathrm{N} / \mathrm{A}$ & 0 & $\mathrm{~N} / \mathrm{A}$ & $\mathrm{N} / \mathrm{A}$ \\
\hline MONEX & 3 & 0,076 & 0,963 & 3 & 0,076 & 0,963 \\
\hline CROBEX & 2 & 0,129 & 0,937 & $\mathrm{~N} / \mathrm{A}$ & $\mathrm{N} / \mathrm{A}$ & $\mathrm{N} / \mathrm{A}$ \\
\hline
\end{tabular}

Notice: Both tests were used at 5\% significance level. In the cases where the sample has T11s1 $=0$ (there are no consecutive VaR breaks), an alternative formula was used in the paper to calculate the first-order Markov likelihood (see Brandolini and Colucci, 2013).

Source: Authors' calculations

As can be seen from Table 4, all of these models have satisfied both tests. It is interesting to note that the cluster of breaks recorded only the unconditional EVT model on the market capital of Croatia. Based on these results, it can not be concluded which the model is most suitable for these markets. For this reason we have ranked the models according to the root mean squared error 
Radivojević N., et al.: Quantifying Extreme Market Risk in the selected Western Balkan

(RMSE). The RMSE results were shown in Table 5.

Table 5. The RMSE statistics

\begin{tabular}{|l|c|c|c|c|}
\hline & \multicolumn{4}{|c|}{ RMES } \\
\hline Stock index & Unc.EVT & EVT-GARCH & EVT-GED & $\begin{array}{c}\text { EVT-GARCH- } \\
\text { skew.t(d) }\end{array}$ \\
\hline BELEXline & 0,156 & 0,158 & 0,245 & 0,242 \\
\hline MONEX & 0,117 & 0,119 & 0,125 & 0,124 \\
\hline CROBEX & 1,125 & $\mathrm{~N} / \mathrm{A}$ & 1,118 & $\mathrm{~N} / \mathrm{A}$ \\
\hline
\end{tabular}

Source: Authors' calculations

The best performer, according to RMES statistics is unconditional VaR model based on EVT. In all markets, the model is best ranked. The exception is only on the Croatian market, where the EVT-GARCH model was achieved better performance.

Unlike the VaR backtesting, the ES backtesting is significantly more complex. This is reason why Basel III standard is not the prescribed a way of backtesting the validity of the ES assessments. To backtesting the various ES models, we ranked the models by their ability to yield minimal loss functions, i.e. the minimum departure from the reported tail loss values. Rankings of the ES models according to RMSE are presented in Tables 6.

Table 6. The RMSE statistics

\begin{tabular}{|l|c|c|c|c|}
\hline Stock index & Unc.EVT & EVT- GARCH & EVT-GED & EVT-GARCH-skew.t(d) \\
\hline BELEXline & 0,432 & 0,455 & 0,443 & 0,416 \\
\hline MONEX & 0,228 & 0,218 & 0,243 & 0,234 \\
\hline CROBEX & 1,835 & N/A & 1,685 & N/A \\
\hline
\end{tabular}

Source: Authors' calculations

According to the RMSE statistic, it can not be concluded which the model is most suitable for these markets. The models are ranked differently in these markets. What can be concluded on the basis of the obtained results of the backtesting is that all EVT-based models can be reliably used in the markets of the selected countries of the Western Balkans, and that the selection of an adequate specification of the $\mathrm{VaR}$ and $\mathrm{ES}$ models depend on the characteristics of the market. 


\section{Validation of the backtesting results}

As it is known that a main drawback of both tests is that they have a questionable statistical power when applied to finite samples (see Christoffersen and Pelletier (2004), Berkowitz et al. (2008), Ziggel et al. (2013) etc). Namely, both tests are developed using asymptotic arguments, which can create difficulties when applied to finite samples. the firs test is asymptotically distributed as $\mathrm{x} 2$ with one degree of freedom under the null hypothesis that the tail probability $(p)$ is the true probability, until second it is asymptotically distributed as $\times 2$ with two degrees of freedom under the null hypothesis that the hit sequence is IID Bernoulli with the mean equal to confidence level for which the $\mathrm{VaR}$ is performed. Asymptotically, that is as the number of observations, $T$, goes to infinity, the $L R_{u c}$ test will be distributed as a $X 2$ with one degree of freedom. It is the same with the $L_{c c}$ test. In large enough samples, the $L R_{c c}$ test will be distributed as a $X 2$ with two degree of freedom. Radivojevic et al. (2016) have shown that when the number of VaR breaks is small, there are substantial differences between asymptotic probability distributions of the considered tests and their finite sample analogues. From this reason, the backtesting results obtained by these tests have to be verified. For that purpose in the paper we used following procedure based on the Monte Carlo simulation: First, we generated 9.999 samples of random IID Bernoulli ( $p)$ variables, where the sample size equals the actual sample, and then, based on these artificial samples, 9.999 simulated LRuc tests were calculated and named. Then, we calculated the simulated $p$-values as the share of simulated LRuc values which are larger than the ones which LRuc test value actually obtained:

$$
p-\text { value }=\frac{1}{10.000}\left\{1+\sum_{i=1}^{9.999} I\left(L \tilde{R}_{u c}(i)>L R_{u c}\right)\right\}
$$

where I(.) takes on the value one if the argument is true and zero otherwise. The same procedure was repeated for conditional coverage test. The results of these simulations are presented in Table 7. Average feasible rates of the $L R_{u c}$ test is 0,737 , until in the case of the $R L_{c c}$ test is 0,691 .

The Monte Carlo testing results confirm the results of previous tests. All tested models can be reliably used in these markets to measure extreme market risk. To verify the validity of the ES model, we used the bootstrap simulation. The RMSE statistics based on the bootstrap simulations are shown in Table 8. 
Radivojević N., et al.: Quantifying Extreme Market Risk in the selected Western Balkan

Table 7. The backtesting results based on the Monte Carlo p-values

\begin{tabular}{|c|c|c|c|c|}
\hline & \multicolumn{4}{|c|}{ The $L_{\text {uc }}$ test } \\
\hline & \multicolumn{2}{|l|}{ Unc.EVT } & \multicolumn{2}{|c|}{ EVT- GARCH } \\
\hline Stock index & Critical value of $L R_{u c}$ & $p$-value & $\begin{array}{c}\text { Critical value of } \\
L R_{u c}\end{array}$ & $\mathrm{p}$-value \\
\hline BELEXline & 0,072 & 0,789 & 0,202 & 0,653 \\
\hline MONEX & 0,015 & 0,901 & 0,113 & 0,737 \\
\hline \multirow[t]{2}{*}{ CROBEX } & 0,356 & 0,551 & $\mathrm{~N} / \mathrm{A}$ & $\mathrm{N} / \mathrm{A}$ \\
\hline & \multicolumn{2}{|l|}{ EVT-GED } & \multicolumn{2}{|c|}{ EVT-GARCH-skew.t(d) } \\
\hline Stock index & Critical value of $L R_{u c}$ & $p$-value & $\begin{array}{c}\text { Critical value of } \\
\mathrm{LR}_{\mathrm{uc}}\end{array}$ & $\mathrm{p}$-value \\
\hline BELEXline & 0,026 & 0,871 & 0,108 & 0,743 \\
\hline MONEX & 0,333 & 0,564 & 0,602 & 0,438 \\
\hline \multirow[t]{3}{*}{ CROBEX } & 0,461 & 0,497 & $\mathrm{~N} / \mathrm{A}$ & $\mathrm{N} / \mathrm{A}$ \\
\hline & \multicolumn{4}{|c|}{ The $L^{1} R_{c c}$ test } \\
\hline & \multicolumn{2}{|l|}{ Unc.EVT } & \multicolumn{2}{|c|}{ EVT- GARCH } \\
\hline Stock index & Critical value of $L R_{c c}$ & $\mathrm{p}$-value & $\begin{array}{c}\text { Critical value of } \\
\qquad R_{c c}\end{array}$ & $\mathrm{p}$-value \\
\hline BELEXline & 1,221 & 0,543 & 2,005 & 0,367 \\
\hline MONEX & 1,455 & 0,483 & 1,848 & 0,397 \\
\hline \multirow[t]{2}{*}{ CROBEX } & 1,930 & 0,381 & $\mathrm{~N} / \mathrm{A}$ & $\mathrm{N} / \mathrm{A}$ \\
\hline & \multicolumn{2}{|l|}{ EVT-GED } & \multicolumn{2}{|c|}{ EVT-GARCH-skew.t(d) } \\
\hline Stock index & Critical value of $L_{\mathrm{cc}}$ & $\mathrm{p}$-value & $\begin{array}{c}\text { Critical value of } \\
\text { LR }_{c c}\end{array}$ & $\mathrm{p}$-value \\
\hline BELEXline & 0,883 & 0,643 & 1,828 & 0,401 \\
\hline MONEX & 1,390 & 0,499 & 0,807 & 0,668 \\
\hline CROBEX & 3,169 & 0,205 & $\mathrm{~N} / \mathrm{A}$ & $\mathrm{N} / \mathrm{A}$ \\
\hline
\end{tabular}

Notice: Significant level of $5 \%$. Samples where the test cannot be computed are omitted due to lack of VaR breaks.

Source: Authors' calculations

Table. 8. The RMES statistics based on the Bootstrap simulation

\begin{tabular}{|l|c|c|c|c|}
\hline Stock index & Unc.EVT & EVT- GARCH & EVT-GED & EVT-GARCH-skew.t(d) \\
\hline BELEXline & 0,332 & 0,335 & 0,351 & 0,328 \\
\hline MONEX & 0,176 & 0,118 & 0,103 & 0,120 \\
\hline CROBEX & 0,902 & N/A & 0,967 & N/A \\
\hline
\end{tabular}

Source: Authors' calculations

As can be seen from Table 4, the models have been ranked differently in different markets, and on the basis of these results it is not possible to draw the conclusion which the model is the most adequate. The general conclusion 
is that VaR and ES models can be reliably used to assess extreme risk in the markets of the selected countries of the Western Balkans.

\section{Conclusion}

As already mentioned in the paper, focusing on extreme loses instead of the entire distribution of portfolio returns is logical, as risk management involves measuring the economic impact of extreme events on the value of the portfolio. Numerous models of EVR-based VaR and ES are proposed by numerous authors. However, empirical research speaks, both in favor and against these models. Namely, the advantages and disadvantages of these models limit their applicability on a certain types of financial markets.

The aim of the paper is to examine applicability of the unconditional and the conditional VaR and ES models based on EVT on the selected markets of the WBC. For the purposes of testing the validity of the VaR model, were used a tests of conditional and unconditional coverage were proposed by Kupiec, or Christifferson. The results of these tests suggested that unconditional and conditional VaR models based on EVT can be reliably used in these markets, in the context of Basel II and III standards. Since these tests are based on certain asymptotic arguments, conclusions that were reached based on them need to be verified. This is why the Monte Carlo testing technique was used. Results of conducted simulations suggest that the VaR forecasts obtained by these models can be trusted and that these models can be reliably used in the emerging markets in terms of the Basel Committee's rules. The RMES statistic of the VaR models show that the best performer was unconditional VaR model based on EVT. In all markets, the model is best ranked, except on capital market of Croatia. For testing the ES models based on EVT, we used the RMES statistics. Also, these results were subject of the verification by used the bootstrap simulation. Based on the obtained data, it cannot be concluded which the model is the most suitable for these markets. Namely, the models are differently ranked in different markets.

The general conclusion is that these models can be reliably used to quantify the extreme market risk in selected capital markets of the WBC, in terms of the Basel Committee's rules.

\section{References}

Balkema, A.A., \& de Haan, L. (1974). Residual Life Time at Great Age. The Annals of Probability, 2(5), 792-804. doi:10.1214/aop/1176996548 
Radivojević N., et al.: Quantifying Extreme Market Risk in the selected Western Balkan

Brandolini, D., \& Colucci, S. (2012). Backtesting value-at-risk: a comparison between filtered bootstrap and historical simulation. The Journal of Risk Model Validation, 6(4), 3-16. doi:10.21314/jrmv.2012.094

Berkowitz, J., Christoffersen, P., \& Pelletier, D. (2011). Evaluating Value-at-Risk Models with Desk-Level Data. Management Science, 57(12), 2213-2227. doi:10.1287/mnsc. 1080.0964

Christoffersen, P., \& Pelletier, D. (2004). Backtesting Value-at-Risk: A Duration-Based Approach. Journal of Financial Econometrics, 2(1), 84-108. doi:10.1093/jjinec/nbh004

Christoffersen, P.F. (2011). Elements of Financial Risk Management. Academic Press.

Daníelsson, J., \& de Vries, C.G. (1997). Tail index and quantile estimation with very high frequency data. Journal of Empirical Finance, 4(2-3), 241-257. doi:10.1016/s0927-5398(97)00008-x

Dimitrakopoulos, D.N., Kavussanos, M.G., \& Spyrou, S.I. (2010). Value at risk models for volatile emerging markets equity portfolios. The Quarterly Review of Economics and Finance, 50(4), 515-526. doi:10.1016/j.qref.2010.06.006

Del, B.E.B., Mora-Valencia, A., \& Perote, J. (2014). VaR performance during the subprime and sovereign debt crises: An application to emerging markets. Emerging Markets Review, 20, 23-41. doi:10.1016/j.ememar.2014.05.001

Embrechts, P., Kaufmann, R., \& Patie, P. (2005). Strategic Long-Term Financial Risks: Single Risk Factors. Computational Optimization and Applications, 32(1-2), 6190. doi:10.1007/s10589-005-2054-7

Gençay, R., \& Selçuk, F. (2004). Extreme value theory and Value-at-Risk: Relative performance in emerging markets. International Journal of Forecasting, 20(2), 287-303. doi:10.1016/j.ijforecast.2003.09.005

Gencay, R., Selcuk, F., \& Ulugulyagci, A. (2003). High volatility, thick tails and extreme value theory in value-at-risk estimations. Insurance: Mathematics and Economics, Vol. 33 (3), 337-356.

Harmantzis, F.C., Miao, L., \& Chien, Y. (2006). Empirical study of value-at-risk and expected shortfall models with heavy tails. The Journal of Risk Finance, 7(2), 117-135. doi:10.1108/15265940610648571

Lee, T., \& Saltoglu, B. (2001). Evaluating Predictive Performance of Value at Risk Models in Emerging Markets: A Reality Check. Working paper.

Louzis, D.P., Xanthopoulos-Sisinis, S., \& Refenes, A.P. (2014). Realized volatility models and alternative Value-at-Risk prediction strategies. Economic Modelling, 40, 101-116. doi:10.1016/j.econmod.2014.03.025

Marinelli, C., d'addona S., , \& Rachev, S.T. (2007). A Comparison of Some Univariate Modelsfor Value at Risk and Expected Shortfall. International Journal of Theoretical and Applied Finance, Vol. 10 (6), 1-33.

McNeil, A.J., \& Frey, R. (2000). Estimation of tail-related risk measures for heteroscedastic financial time series: an extreme value approach. Journal of Empirical Finance, 7(3-4), 271-300. doi:10.1016/s0927-5398(00)00012-8

Neftci, S.N. (2000). Value at Risk Calculations, Extreme Events, and Tail Estimation. The Journal of Derivatives, 7(3), 23-37. doi:10.3905/jod.2000.319126

Radivojevic, N., Cvjetkovic, M., \& Stepanov, S. (2016). The new hybrid value at risk approach based on the extreme value theory. Estudios de economía, 43(1), 2952. doi:10.4067/s0718-52862016000100002 
Radivojević N., et al.: Quantifying Extreme Market Risk in the selected Western Balkan

Radivojevic, N., Curcic, N., Milojkovic, D., \& Miletic, V. (2016). Testing value-at-risk models in emerging markets during crises: a case study on South Eastern European countries. The Journal of Risk Model Validation, 10(2), doi:10.21314/jrmv.2016.153

Rossignolo, A.F., Fethi, M.D., \& Shaban, M. (2012). Value-at-Risk models and Basel capital charges: Evidence from Emerging and Frontier stock markets. Journal of Financial Stability, 8(4), 303-319. doi:10.1016/j.jfs.2011.11.003

Rossignolo, A.F., Fethi, M.D., \& Shaban, M. (2013). Market crises and Basel capital requirements: Could Basel III have been different? Evidence from Portugal, Ireland, Greece and Spain (PIGS). Journal of Banking \& Finance, 37(5), 13231339. doi:10.1016/j.jbankfin.2012.08.021

Şener, E., Baronyan, S., \& Ali, M.L. (2012). Ranking the predictive performances of value-at-risk estimation methods. International Journal of Forecasting, 28(4), 849-873. doi:10.1016/j.ijforecast.2011.10.002

Sukcharoensin, P., \& Sukcharoensin, S. (2010). Applications of Statistical Distributions in Risk Management. European Journal of Economics, Finance and Administrative Sciences, 65-84; 26.

Ziggel, D., Berens, T., Weiss, G.N.F., \& Wied, D. (2013). A New Set of Improved Value-at-Risk Backtests. SSRN Electronic Journal, doi:10.2139/ssrn.2316134

Zikovic, S., \& Pecaric, M. (2010). Modelling extreme events: Application to Zagreb stock exchange. Ekonomski pregled,Vol. 61 (1-2), 20.

Zikovic, S., \& Aktan, B. (2009). Global financial crisis and VaR performance in emerging markets: A case of EU candidate states - Turkey and Croatia. Journal of Economics and Business, Vol. 27 (1), 149-170.

Zikovic, S. (2008). Quantifying extreme risks in stock markets: A case of former Yugoslavian states. Zbornik radova Ekonomskog fakulteta u Rijeci, Vol. 26 (1), pp. 41-68. 